\title{
The Changing Pattern of Intimate Relationship and the Influence of Technology on Youth in Socio-Cultural Attachment of Bangladesh
}

\author{
Mehjabin Haque ${ }^{1}$; Md. Muniruzzaman²; Israt Eshita Haque ${ }^{2}$ \\ ${ }^{1}$ BSS and MSS in Sociology, University of Dhaka, Faculty of Social Science, Department of Sociology, Bangladesh \\ ${ }^{2}$ Assistant Professor, Noakhali Science and Technology University, Faculty of Social Science and Humanities, \\ Department of Sociology, Bangladesh \\ Email: munir.zaman02227@gmail.com
}

http://dx.doi.org/10.47814/ijssrr.v5i3.195

\begin{abstract}
Intimacy or intimate relationship means the experience of a strong feeling of closeness, the emotional bonding between male and female. An intimate relationship has a sexual desire which is biologically driven. In the present era, the intimate relationship of young people has transformed due to the influence of technology in Bangladesh. Technological evaluation and social media are bringing one of the most important revolutions in the history of mankind. But the excessive use of technology may create a haphazard situation with young people despite having some positive aspects. The present study aims to explore the influence of technology on youth with the gradual transformation of intimate relationships from pre-modern to post-modern societies. The study was qualitative in nature in which multiple case studies were employed. The study found that the influence of technology is gradually being increased in the pattern of intimate relationships among the youths. Technology has a great influence on the system of intimate relationships such as marriage, divorce, premarital and extramarital relationships. The easy access to the internet and the excessive use of social media affects the pattern of intimacy among the youths in the post-modern era. The study also found that young people are now involved in premarital and extramarital relationships by using internet-based technology which is one of the responsible factors for increasing domestic violence and divorce rate.
\end{abstract}

Keywords: Intimacy; Relationship; Technology; Social media; Young people

\section{Introduction}

Intimacy represents one of the most important concepts in defining the current context of intimate partner relationships, whether in marital or non-marital love affairs. In recent years, intimacy has received much attention in both popular discourse and scholarly work. In this study, an intimate relationship refers to the relationship between two partners. It may be a married couple or may engage in love affairs. In a long-term relationship, the higher level of intimacy and romantic affairs in a longer duration are connected with sexual desire in both men and women partners. (Lankveld, Jacobs, Thewissen, Dewitte, \& Verboon, 2018). Intimacy or intimate relationship is a widespread term across cultures throughout the 
world. It may also be considered as passionate love that has a deep and strong emotional involvement between individuals. Intimacy or intimate relationship represents a positive effect among individuals where the concepts of 'you' and 'me' transforms the concept of 'us'. Those who are involved in a romantic intimate relationship, are emotionally dependent on their partners' happiness within an intimate relationship. (Kawamichi, et al., 2016)

As a third-world developing country, education is not available for everyone in Bangladesh and women have not still come out from their traditional outlook. In spite of having many hindrances, our country is now achieving many developments in the spheres of communication technology. These are the consequences of the process of globalization. The term globalization refers to cultural shifts in favor of materialism, consumerism, individualism, and the eroding of "traditional" family systems. (Wallerstein, 1989). Widespread networks of mobile phones and satellite channels affect almost every aspect of our social life. Our young generations are addicted to advance technology. Widespread western influences and cultural mixture greatly affect personal lives particularly in intimate partner relationships of young generations. In the present era, both males and females are conscious about their self-development and both are also concerned about gender equity in their personal life.

Technology brings more opportunities that sometimes create violence in intimate relationships among the partners. (N.Duerksen \& Woodin, 2019) The increasing use of technology may create a problematic situation and when their partners like to express their feelings through social media. Online social relationships and face-to-face relationships have been the potential to blur boundaries by the internet. Blurred boundaries have a negative impact on the intimate relationship which is occurred for excessive use of technology. (Rossouw \& Leggett, 2014)

Intimate relationship pattern is changing because of the overuse of internet technology and relationships are becoming more fragile. It also creates isolation in the close relationship. In the present era, people are too busy to do their respective works and to mitigate their everyday growing demand. As a consequence of this, people are involved in internet technology to continue the relationship with relatives and for various purposes (Pervin \& Hussain, 2018). In recent years, young generations are technologically more advanced and they are plagued by technological issues. In this study, researchers wanted to represent the influence of technology on love and intimacy among the youths. This study also aims to point out that, what does intimacy and love mean and what is the changing pattern of love and intimacy. The findings can be helpful to develop a clear conceptualization on changing intimate partner relationships from the perspective of third-world countries like Bangladesh. However, a good number of works about the intimate relationship have already been done, but the influence of technology on the changing pattern of intimate relationships are not explored through any appropriate research especially in a third world country like Bangladesh. This study is an attempt to cover this gap in the academic field.

\section{Aims and Objectives}

The purpose of this study is to present an adequate analysis of the changing pattern of intimate relationships and the influence of technology on it among the youths in the socio-cultural attachment of Bangladesh. This study attempts to represent socio-demographic profiles of young males and females to understand their relationship patterns. The pattern of love and intimacy is changing in the present era. Relationship pattern varies from culture to culture, society to society and country to country. For this reason, this research tries to investigate the nature of love and intimacy and the influences of technology on love and intimacy in Bangladesh. The study also tried to find out the multidimensional impacts of the transformation of intimacy and technological effect on it among the youths.

\section{Methodology}

In this study, specific efforts have been made to identify the relationship between the influence of technology on youths and the changing pattern of intimacy. Researchers followed the qualitative method 
for data collection because the intimate relationship is a kind of emotional attachment along with complicated issues of the human mind. Multiple case studies were conducted for data collection from the students of two public and private universities situated in Dhaka, Bangladesh. Both primary and secondary data were used for this study. Secondary data was collected from books, journal articles, research papers, and some reliable websites. Dhaka University (Public university) and BRAC University (Private University) were selected purposively to collect data from the students. A total of 30 respondents were selected by following snowball sampling procedure. From them, 15 were selected from Dhaka University and the other 15 were selected from BRAC University. Dhaka University is the leading public university in Bangladesh and BRAC University is one of the leading private universities in Bangladesh. Since the researchers wanted to explore a very sophisticated issue like the intimate relationship, they used purposive sampling method for selecting the universities and the snowball sampling method for selecting the respondents from where they can get more appropriate data for this study. 10 males and 5 female respondents were selected from each university to collect data The researchers also followed a comparative discussion between public and private university students' outlook about technological use and how to maintain their intimate relationship with their partners.

\section{Theoretical Perspective of Intimate Relationships}

The concept of intimate relationships has been taken up differently by sociologists of contrasting persuasions. Many of the perspectives adopted even a few decades ago now seem much less convincing in the light of recent research and important changes in the social world. Nevertheless, it is valuable to trace shortly the evolution of sociological thinking before turning to contemporary approaches to the study of the intimate relationship. Anthony Giddens, Ulrich Beck, Zygmunt Bauman are some pioneer sociologists who argue the process of modernization did not come to an end rather it continues into the contemporary era. In the nature of intimacy and in the aspect of the intimate relationship, revolutionary changes have occurred in the postmodern and late modern societies (Muniruzzaman, 2017). Recent perspectives have been used in this research to explain the changing pattern of intimate relationship.

Table 1:Summary of the theoretical discussions

\begin{tabular}{l|l}
\hline Name & Key Points \\
\hline "Transformation of & $\begin{array}{l}\text { Giddens focused his discussion on "De-traditionalizing" in the realm of } \\
\text { intimate relationships. To him, the discussion of 'De-traditionalizing' is } \\
\text { closely related to the idea of globalization }\end{array}$ \\
$\begin{array}{l}\text { Intimacy: Sexuality, } \\
\text { Love, and eroticism in }\end{array}$ \\
$\begin{array}{l}\text { Modem Societies" } \\
\text { (Giddens, 1992). }\end{array}$ \\
$\begin{array}{l}\text { The shift from romantic love to pure or confluent love. } \\
\text { Romantic love arose with some sources of passionate love. }\end{array}$ \\
$\begin{array}{l}\text { In the sense of sexual exclusiveness, unlike romantic love confluent love is } \\
\text { not necessarily monogamous. }\end{array}$ \\
$\begin{array}{l}\text { Love" (Beck \& Beck- } \\
\text { Gernsheim, 1995). }\end{array}$ \\
$\begin{array}{l}\text { They examined the tumultuous nature of personal relationships, marriage, } \\
\text { and family patterns against the backdrop of a rapidly changing world. }\end{array}$ \\
$\begin{array}{l}\text { Relationships in our modern age are about much more than relationships, so } \\
\text { to speak. Nowadays everyone is on the search for the right way to live. People } \\
\text { are struggling for their status in all aspects of intimate relationships like love, } \\
\text { marriage, contractual marriage, divorce, and so on. }\end{array}$ \\
$\begin{array}{l}\text { Bauman used the metaphor "liquid" to describe modern society which he saw } \\
\text { as characterized by constant change and lack of lasting bonds. }\end{array}$ \\
$\begin{array}{l}\text { Le argued that in a world of rampant "individualization" relationships are a } \\
\text { mixed blessing and they are fulfilled with conflicting desires which pull in } \\
\text { different ways. }\end{array}$
\end{tabular}


Table 1 shows the major theories of intimacy discussed by sociologists with their basic arguments. Some arguments are strongly applicable to this study. In the following sections, some concepts have been applied for understanding the transformation of intimacy in Bangladesh.

\section{Changing Pattern of Intimate Relationship from Pre-modern to Postmodern Society and the Influence of Technology}

Intimate relationships are gradually being transformed over the eras and the changes in human intimacy lead to changes in the overall social system. In traditional societies, love means love after marriage. In the past love before marriage was strictly prohibited in Bangladesh. Not only that life partners were selected by parents and sometimes they could not express their opinion before marriage, especially the females. At that time young people had very little opportunity to involve in a love relationship. Because marriages occurred at very early ages.

If we study the love stories of pre-modern society we find that most of them came to an end with tragedy. Although most of them were myth or simply story, they influenced the trends of the people of that time. At that time premarital and extramarital relationships were very rare. The success rate of premarital love was very poor, especially in Muslim countries. From the Muslim religious perspective, the intimate relationship before marriage was strictly prohibited. So, these relationships would not be successful because of religious values.

But nowadays the patterns, as well as trends, of intimacy are gradually changing. According to postmodern thinkers, rapid changes have occurred in the perspective of intimate relationships or the nature of love relationships in post-modern societies. Some new forms of intimacy such as confluent love, liquid love, plastic sexuality, etc. are prevailing in this present era of late modern society (Giddens, 2006). In the post-modern period, married people are not bound to stay forever with their partners if relationships do not work properly. They have lots of choices. The meaning of romantic love is that once anyone had married he/she was stuck with each other; it was not mandatory how the relationship developed. The confluent love and pure relationship were introduced by Giddens. The confluent love is contingent and it is not monogamous in the sense of sexual exclusiveness. The pure relationship is an ideal type of relationship where emotional intimacy is the basis of a love relationship the people develop their relationship by understanding and depending on each partner. Another concept introduced Giddens is plastic sexuality which is referred to the flexibility of exotic expression in individual choice along with frameworks of social norms. (Giddens, 1992). The new forms of intimacy of the present era such as confluent love, liquid love, pure relationship, plastic sexuality, etc. are gradually spreading due to the widespread influence of information technology.

\section{Data Analysis}

\section{Socio-Demographic Profile of the Public University Students}

The information of the study was constructed by the researchers from the young age people (aged 20-27) of Dhaka city and these respondents were involved in intimate relationships (love affair or married). Socio-demographic data was gathered from each participant concerning their gender, age, religion, educational qualification, and most importantly relationship status. The information of the respondents was collected extensively to analyze the in-depth condition of the relationship patterns of the respondents. The profile of young age people presented to analyze the socio-demographic with relationship condition of young male and female in Bangladesh. 
Table-2: Socio-demographic Profile of Public University Students

\begin{tabular}{|c|c|c|c|c|c|}
\hline $\begin{array}{c}\text { Case Study (Case) } \\
\text { No. }\end{array}$ & Gender & Age & Religion & $\begin{array}{l}\text { Educational } \\
\text { Qualification }\end{array}$ & Relationship Status \\
\hline Case-1 & Male & 22 & Muslim & Under Graduation & Love Affair \\
\hline Case-2 & Male & 21 & Muslim & Under Graduation & Love Affair \\
\hline Case-3 & Female & 22 & Muslim & Under Graduation & Love Affair \\
\hline Case-4 & Male & 24 & Muslim & Graduation & Married \\
\hline Case-5 & Male & 21 & Hindu & Under Graduation & Love Affair \\
\hline Case-6 & Female & 24 & Muslim & Graduation & Married \\
\hline Case-7 & Female & 24 & Buddhist & Graduation & Love Affair \\
\hline Case- 8 & Male & 22 & Muslim & Under Graduation & Love Affair \\
\hline Case-9 & Male & 21 & Muslim & Under Graduation & Love Affair \\
\hline Case-10 & Male & 24 & Muslim & Graduation & Love Affair \\
\hline Case-11 & Female & 22 & Muslim & Graduation & Engaged \\
\hline Case-12 & Male & 26 & Muslim & Post-Graduation & Married \\
\hline Case-13 & Female & 21 & Muslim & Under Graduation & Love Affair \\
\hline Case-14 & Male & 24 & Muslim & Graduation & Love Affair \\
\hline Case-15 & Male & 27 & Hindu & Post-Graduation & Married \\
\hline
\end{tabular}

Source: Data collected from the field

Table 2 shows the socio-demographic condition of young people who are currently studying at Dhaka University. In the gender and age distribution, ten respondents are male and five respondents are female and among fifteen case studies, all respondents are aged between 20-27 years old. As a Muslim country, almost all the respondents are Muslim. Among fifteen respondents, only three are non-Muslim (two Hindu and one Buddhist) and the other twelve are Muslims. All respondents are University students among them seven respondents are under-graduate students, six are graduate students and two are postgraduate students. A maximal portion of the respondents are involved in a love affair and four are married and one is officially engaged with someone. Remarkable diversity can also be found that relatively young people like to involve intimate or love relationship rather than marriage. They think that marriage is a matter of many responsibilities.

\section{Socio-demographic Profile of the Private University students}

Table-3: Socio-demographic Profile of Private University Students

\begin{tabular}{|c|c|c|c|c|c|}
\hline $\begin{array}{c}\text { Case Study } \\
\text { (Case) No }\end{array}$ & Gender & Age & Religion & $\begin{array}{c}\text { Educational } \\
\text { Qualification }\end{array}$ & $\begin{array}{c}\text { Relationship } \\
\text { Status }\end{array}$ \\
\hline Case-1 & Male & 25 & Muslim & Post- Graduation & Married \\
\hline Case-2 & Female & 23 & Muslim & Under Graduation & Love Affair \\
\hline Case-3 & Male & 21 & Muslim & Under Graduation & Love Affair \\
\hline Case-4 & Male & 20 & Muslim & Under Graduation & Love Affair \\
\hline Case-5 & Male & 23 & Muslim & Graduation & Love Affair \\
\hline Case-6 & Female & 26 & Hindu & Post-Graduation & Married \\
\hline Case-7 & Male & 21 & Muslim & Under Graduation & Love Affair \\
\hline Case-8 & Female & 24 & Muslim & Graduation & Love Affair \\
\hline Case-9 & Male & 23 & Muslim & Under Graduation & Love Affair \\
\hline Case-10 & Male & 21 & Muslim & Under Graduation & Love Affair \\
\hline Case-11 & Female & 25 & Muslim & Post-Graduation & Married \\
\hline Case-12 & Male & 23 & Muslim & Graduation & Love Affair \\
\hline Case-13 & Male & 23 & Muslim & Graduation & Love Affair \\
\hline Case-14 & Male & 20 & Hindu & Under Graduation & Love Affair \\
\hline Case-15 & Female & 23 & Muslim & Graduation & Love Affair \\
\hline
\end{tabular}

Source: Data collected from the field 
Table 3 shows the socio-demographic condition of the students of a Private University (BRAC University). The attitude of the students of the private university towards intimate relationships is different from public University. In our country, most of the higher-class parents can afford to send their children to private universities for pursuing higher education. On the other hand, most of the public university students are lower class, lower middle class and some of them belong to the higher class. In the gender and age distribution, 10 respondents are male and 5 respondents are female and among fifteen case studies, all respondents are aged between 20-26 years old. Among fifteen respondents, only two are Hindus and thirteen are Muslims. Among all the respondents seven respondents are under-graduate students, four are graduate students and three are post-graduate students. The most important distribution is relationship status where twelve young people are involved in premarital love affairs and the other three are married. Hence, the socio-demographic backgrounds of the respondents including young people from public and private university differ from their attitude, class, and educational duration also and can be analyzed from different points of view.

\section{Free Selection of Spouse is common Trend than Arranged marriage}

The marriage system of any society depends on their cultural and socio-economic conditions of the society. Without emphasizing cultural factors, the knowledge must not be complete (AHMED, 1986). Young people of Bangladesh were more enthusiastic about arranged marriage and they used to marry whomever their parents liked. But now our new generation is more comfortable choosing their life partner. Due to this, the number of arranged marriages is decreasing day by day. With the blessing of technology, young people can express their feelings without any intervention. Most parents have a positive outlook about the love marriage of their children. Although some parents believe in the previous tradition, they are much less in number. For instance, one of the young male respondents expressed his intimate relationship's condition in the following way:

I am an undergraduate student at Dhaka University. When I was a student of the second year, I was involved in a relationship with my classmate and this relationship is continuing. After involving the relationship, I was worried and shared with my parents about this matter. Fortunately, my parents cordially accepted my girlfriend as a family member. Some days ago, we engaged officially and after finishing our study we will get married. We both are blessed to have such a nice family indeed.

This study shows a noticeable thing is that some respondents struggled to manage their families. One of the female respondents claimed:

I am a post-graduate student and I was involved in a premarital love relationship. After knowing our relationship, my parents didn't take it positively, but I was determined about my commitment. At last, my parents couldn't but accept our relationship and we got married. At the very beginning of our conjugal life, my husband had just joined his new job. We talked a lot on the phone and chatted over messenger because his working place was out of Dhaka city. But now we stay together. After facing some continuous struggle now we are happy and our parents are also satisfied with us.

Both of these respondents acknowledge the role of information technology to build up and maintain their relationships. They mentioned that they used to communicate with each other over the phone and on other social media like Facebook, Messenger, and WhatsApp.

\section{People with Young Age is getting less Committed to the Relationship for Technological Interference}

In recent years, there has been excessive use of technology in everyday life and most importantly all young people in Bangladesh have access to the internet. Almost all young people are the owner of a cell phone, have a laptop, and have a profile on different social networking sites (McDaniel \& Coyne , 
2016). Excessive use of technological devices creates interruptions in intimate relationships. Not only that people at a young age are less committed to their relationship for technological interference. Because nowadays finding new partners by using different social media and other mediums of communication is very easy. As young people have many options, they are not concerned about their commitment, and sometimes they are also confused with their relationships. If there are any ups and downs in their relationship, they can easily get involved with another one through technology (Facebook, Viber, Imo, Instagram, and so on). On the other hand, some young people don't like to get involved in any commitment, because, they don't like to take responsibility. Unfortunately, they get involved just to enjoy the relationship which doesn't go with our culture of Bangladesh.

This study shows a noticeable thing is that some respondents are less committed with their partners for the easier and excessive use of technology. One of the respondents claimed:

I am an undergraduate student at Dhaka University. When I was in my first year, I was involved in a relationship with someone through Facebook who was a job holder. He wanted to talk or meet several times, but I was too much busy with my study and my friend circle. He did not tolerate my friends. He was upset with me because I couldn't give him sufficient time. One day he suddenly got married without informing me. I was shocked by this unexpected news. After that, I talked to several people and tried to get involved in alternative relationships but I am not committed to them.

Some people who do not believe in marriage. For this reason, they don't get involved in commitment. They think that technology can fulfill their all needs. Another respondent said that:

I don't believe in commitment and marriage despite being in a relationship. We both know that we will never marry anyone. But we both enjoy the company of two people and we both don't believe in marriage. If technology can give us all the benefits, what is the need for marriage? Marriage makes kinds of unnecessary responsibilities and emotional attachment that is not suitable for me.

\section{Rising Uncertainty and Anxiety in Intimate Relationship for Technology}

Mobile phones have become one of the most pervasive interpersonal media, especially for college students (Student Affairs Administrators in Higher Education, 2008). Accordingly, the study of mobile communication (i.e., communicating through mobile phones including voice calls or text messaging) has been burgeoning in recent years (e.g., Katz, 2008; Katz \& Aakhus, 2002). Mobile communication Mobile phones have become one of the most pervasive interpersonal media, especially for college students (Student Affairs Administrators in Higher Education, 2008). Accordingly, the study of mobile communication (i.e., communicating through mobile phones including voice calls or text messaging) has been burgeoning in recent years (e.g., Katz, 2008; Katz \& Aakhus, 2002). Mobile communication Mobile phones have become one of the most pervasive interpersonal media, especially for college students (Student Affairs Administrators in Higher Education, 2008). Accordingly, the study of mobile communication (i.e., communicating through mobile phones including voice calls or text messaging) has been burgeoning in recent years (e.g., Katz, 2008; Katz \& Aakhus, 2002). Mobile communication The mobile phone is one of the pervasive communication media for young people especially those who are involved in an intimate relationship and are more dependent on mobile phones or other social media rather than face-to-face communication. For this, communication through mobile phones like video calling, text massaging are common trends in the recent era. (Jin \& Peña, 2010) 
Figure 1

Conceptual Model of technological Interference in Intimate Relationship

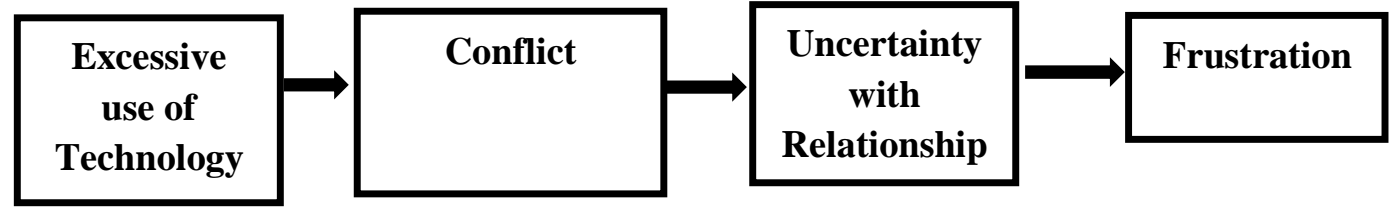

Figure 1 shows the conceptual model of technological interference in intimate relationships. Excessive use of technology and the availability of multiple options for choosing partners via technology may lead to conflict and increase uncertainty in a relationship and gradually it makes anxiety along with frustration.

Some young people are facing lots of problems with the excessive use of technology. As a result of excessive use of technology, they give less time to each other and they are not pleased with their relationship. One of the respondents from a public university expressed that:

When I was a student of the third year, from that time I have committed to a relationship with my best friend. Despite the commitment, I feel uncertainty with him. Because my boyfriend is addicted to social media and sometimes he talks with his students (he takes classes in a coaching center) for a long time especially with female students. That's why I feel uncertain about our relationship. This is so much irritating for me. I am so much frustrated. For frustration, I cut off my hand, and another day I took sleeping pills also.

For the increasing use of technology, the tendency of doubt is increasing among the couples and sometimes their suspicions come true. Another respondent who is a student of Private University added the following way:

I had a strong commitment with my girlfriend and both of our families knew about our relationship. Suddenly I saw a lot of changes in her behaviors. Almost all the time she was busy on messenger or phone. When I asked her, she said that she was busy with her friends or family members. At first, I was convinced by her excuses, but one day I was able to understand that she maintained two relationships simultaneously and they were introduced by Facebook.

\section{Disappearing Traditional Lifestyles, Local Customs and Religious Values}

In the past, almost all marriages were arranged marriages in Bangladesh. At that time parents, particularly the father took all decisions regarding the marriage of his son or daughter. Men got married around the age of twenty-five or older. On the other hand, women got married between ages fifteen and twenty and their husbands' age was normally more than ten years older. When parents decided that their children are ready to marry, that time they communicated with agencies, relatives, and friends to find a suitable one. Dowry and the types of gifts to be made to the groom were very common issues. At that time, divorce was one kind of social stigma, and the divorce rate was very low. (Countries and their Cultures, n.d.) Most of the people of Bangladesh are Muslims. Besides that, there are several religious people like Hindu, Buddhist, and Christian. Among them, Hindu is the second-largest religion in Bangladesh. In the case of Hindu marriages, there are separate customs and religious values. In the Hindu social customs, marriage was a religious duty, not a contract and there have no legal proceedings rather social customs. But the rituals of marriage vary from caste to caste. (The Lawyers and Jurists, n.d.) But Hindu rituals and customs are disappearing day by day. Not only Hindu religion but other religious cultures are also disappearing and cross-religious or cross-caste marriages have become very prevalent nowadays. At one time, if anyone marries someone of another religion, society would not accept his/her. 
But the environment has greatly changed now. Some have an intimate relationship with someone of another religion. Not only that, they are strongly committed to each other for marriage and in some cases, their family also accepts their relationship. One of the respondents cited that:

My partner has come from another religion. We both had a strong commitment and for this dedication, we got married. My parents knew about our relationship and they cordially accepted our marriage. On the other hand, my in-lows family did not accept it first. But for the time being, they accepted our relationship. The two of us come from two religions and we have some problems in adjusting. Despite problems, we both respect our religions. We judge people as human beings, not in terms of religion.

\section{Increasing Divorce Rate}

The divorce rate in Bangladesh is gradually increasing day by day. The divorce rate in Dhaka city has increased in a significant number at the time of COVID-19 pandemic. In the five months from June to October 2020, the divorce rate has increased largely. Per day 39 divorces have occurred which means one divorce per 37 minutes. In this five months 5970 divorces have been taken place in Dhaka city. Divorce has increased 29.78\% in the first five months of 2020 (Mannan, 2020).

The Bangladesh Bureau of Statistics (BBS) data says that divorce has been increased for years. Not only that divorce is a more and more common trend among educated husbands and wives. The CBS' study of Vital Statistics, published in June 2019, says that divorce cases in 2019 have increased by 17 percent compared to 2018 (Prothom Alo.com, 2018).

At one time, Bangladeshi women could not think about divorce. But now women are independent. They do not tolerate any oppression and they protest against injustice. That's why, in the last seven years, the divorce rate application has increased by a massive 34 percent throughout the country according to data compiled by the Bangladesh Bureau of Statistics (BBS). "At least 50,000 divorce applications were filed in Dhaka North and South City Corporations in the past six years, which means on average one divorce application was filed every hour," the report reads. Most of the applications for divorce came from women and the most common reasons were torture for the dowry, suspicious attitude of the husband, drug addiction, extramarital relationships, addiction to social media etc. On the other hand, the most common reasons cited by husbands were wives not leading lives according to Islamic rules, negligence to husband's family members, bad temper and, disobedience. (Nowshin, 2018)

About $75 \%$ of the divorce applications were filled by women. Suspicion is enough to ruin a relationship and many get divorced for this doubt. One of the respondents discussed her worst experience. Most of the married women realized that divorce was the ultimate solution to their problems. The number of divorces was 4574 under the two-city corporation area from January to July 2018. But the number increased to 6232 in the first six months of that year (FUAD, 2019).

Some young people are betrayed for getting involved in an intimate relationship through social media. There are many opportunities to hide something on social media and people represents themselves as artificial way. It is better not to believe blindly in a sensitive issue like intimate relationship. One respondent requested everybody not to involve any relationship through social media. She shared his story for creating consciousness among young people, especially women. She said that:

Through Facebook I got someone and I thought, he loved me a lot. I decided I would marry him. He also committed with me and he acted that he can't live without me. Unfortunately, his love was fake. One day he told me let's get married and I agreed with his proposal without any thinking. After getting married, we went to Cox's Bazar where we spent our days very happily. After coming back, I realized that his attitude was changing. Some days later, he requested me to give him a divorce, 
because his parents were unable to accept me. Then we get divorced mutually and very few people know about our marriage. Recently I have been involved in another relationship who is my best friend and he knows about my past. He has no headache about this matter.

\section{Extra-Marital Relationship}

Marriage is an enduring relationship where males and females acquire social, religious, and legal recognition to live together. It is a lifetime bonding that creates mutual obligations between husband and wife. No religion can permit to satisfy their biological need without marriage. Extramarital affairs are considered as any relationship (whether physical intercourse or not) outside the marriage where married persons are engaged in a relationship with someone other than their husbands or wives (Jahan, Rahman, Chowdhury, \& Chowdhury, 2017). Few studies have been conducted about extramarital affairs in Bangladesh and some related issues. Till now, there is no sufficient data concerning factors responsible for extramarital issues in Bangladesh. Bangladesh as a conservative country, an extramarital affair is much more confidential. Availability of online social media is the consequence in many more spouses searching for love or involving intimate relationships. Extramarital relationships ruin the beautiful family relationship and increase conflict between husband and wives, for this reason, children are affected by its harmful effects.

There are so many social media like Facebook, WhatsApp, IMO, Viber, and so on where married persons can express their feeling and seek an extramarital relationship. It is kind of the worst thing that destroys the trust in a relationship and trust is the precondition to continue a longtime relationship. Not only that extramarital affairs have major negative effects leading to divorce in Bangladesh.

Even some young people get involved in a relationship with a married person. The reason for their relationship is an emotional attachment, besides that personal benefit. One of the respondents commented that:

I and my girlfriend did a part-time job where we got a handsome boss. He was a married person with two beautiful kids and they are a happily married couple. My girlfriend talked with him and she gave me an excuse that they talked with each other for the sake of official need. That guy gave my girlfriend all kinds of advantages from others. I took my girlfriend's password from her because I was suspicious of their attitude. One night I woke up suddenly and logged in with her password and saw that she had a lot of emotional talk with that guy like husband-wife. Not only that they were planning to go far away. Then I told his wife about this matter and she was shocked. My girlfriend apologized to me and she would never do such a thing again.

Young people are deceiving for the result of an extramarital affair. Many people hide their marriage and run away after getting benefits. Another respondent described her difficult true experience. She added:

I had a love affair with someone through Facebook. He was good looking and I was fascinated to hear his talking style. We had a good time. One day his wife understood that something is happening badly. They did not live together because his wife worked in another city. After understanding his husband's extramarital affair, she gave me a phone call and requested me not to communicate with him. I became senseless after hearing this unexpected news. I missed the moments that I spent with him. Unfortunately, he cheated on me and he cheated with his wife also. The pain of being deceived is terrible which both his wife and I understood. After that. I never dared to fall in love with anyone. I have married a person chosen by my parents and Alhamdulillah my husband is an amazing person. 


\section{Merits and Demerits Associated with technology Use in Intimate Relationship}

\begin{tabular}{|c|c|c|}
\hline \multicolumn{3}{|c|}{ Merits and Demerits Associated with technology Use in Intimate Relationship } \\
\hline Application & Merits & Demerits \\
\hline $\begin{array}{c}\text { Mobile } \\
\text { (Smart Phone) }\end{array}$ & $\begin{array}{l}\text { - Talk any time } \\
\text { - In touch with family } \\
\text { - Can get emergency update } \\
\text { - Capture picture } \\
\text { - Can share picture } \\
\text { - Reduce parents worry }\end{array}$ & $\begin{array}{l}\text { - Provide misinformation } \\
\text { - During dating time, may ring another } \\
\text { phone. } \\
\text { - For checking call list or massage, it } \\
\text { may create odd situation with } \\
\text { partners. }\end{array}$ \\
\hline $\begin{array}{l}\text { Face book or } \\
\text { Instagram }\end{array}$ & $\begin{array}{l}\text { - Can share photo on his or her } \\
\text { wall } \\
\text { - Share feeling by writing } \\
\text { - Stay connected with friends } \\
\text { - More open than phone }\end{array}$ & $\begin{array}{l}\text { - By contact a person for buildup } \\
\text { intimate relationship. } \\
\text { - Explore extramarital relationship. } \\
\text { - Can represent artificial way. } \\
\text { - Flirt to keep relationship }\end{array}$ \\
\hline $\begin{array}{l}\text { Messenger, } \\
\text { WhatsApp, } \\
\text { Viber, Imo }\end{array}$ & $\begin{array}{l}\text { - Not expensive } \\
\text { - One kind of fun } \\
\text { - Instant interaction } \\
\text { - Chat room gives people more } \\
\text { space } \\
\text { - Easy way for audio and video call }\end{array}$ & $\begin{array}{l}\text { - People chat by these devices with } \\
\text { unknown person } \\
\text { - Build an intimate relationship like } \\
\text { wife or gf } \\
\text { - Fall in love without knowing each } \\
\text { other }\end{array}$ \\
\hline Online Shopping & $\begin{array}{l}\text { - Shopping staying at home } \\
\text { - Buying gifts for special one } \\
\text { - Reduce time } \\
\text { - During this pandemic situation, } \\
\text { it's very popular }\end{array}$ & $\begin{array}{l}\text { - Worst product for without seeing } \\
\text { - More attention on shopping than } \\
\text { partner. }\end{array}$ \\
\hline Pornography & - Can change sex life & $\begin{array}{l}\text { - Bad addiction } \\
\text { - Damages intimacy } \\
\text { - Destroy physical attraction along } \\
\text { with self-esteem. } \\
\text { - Disrespect of partner } \\
\text { - Pave the way of divorce and } \\
\text { extramarital affairs } \\
\text { - Unrealistic expectation. }\end{array}$ \\
\hline
\end{tabular}

\section{Discussion}

Intimacy or intimate relationship is a widely used term all over the world and it is also a basic need for human life. The pattern of intimacy or intimate relationships may be changed. We need to be concerned about the negative aspects of the changes. Some studies have focused on modern technology like mobile phones, social media, laptops, internet that can be used in many ways for getting involved in intimate relationships. Not only that technology can be employed to build relationship formation, maintenance, and growth. Few studies have examined that intimate relationship pattern is changing for the massive globalization where ideas, values, customs, lifestyle diffuse faster than past. Divorce was taboo at once but now it is a little bit normal in our country like western countries. Unfortunately, the divorce rate is increasing alarmingly (Afroz, 2019). Moreover, a good number of studies have been published by sociologists, researchers, public health workers regarding intimacy or intimate relationship, technological effects toward them, their feelings, and so on. It may provide a partial picture of the issues. This study has tried to explore the transformation of intimate relationships and the influence of technology on intimacy among the youths in Bangladesh. 
From the above discussion, the study shows that young people who are involved in intimate relationship and marital relationships from public and private universities have been taken as a sample of this research lived in Dhaka city, Bangladesh. Public and private University students have a few differences in their intimate relationships. In this study, researchers have been talked with several young people, some cases were almost similar. That's why important case studies have been added. The key findings of the case studies are the following:

$>$ The notable thing is that Tuition fees at private the university of Bangladesh are so high which is difficult to afford for the middle-class family. On the other hand, it is very difficult to get a chance in a public university, but the cost is much less which is easy to manage for the middle or lower class. Students of public universities are more serious about the intimate relationship than the students of private universities. Not only that students of private universities use mere technological devices rather than private universities. Most of the students of public University live in residential hall and hall WIFI conditions is so poor.

$>$ The arranged marriage rate is disappearing day by day and the love marriage rate is increasing in a significant number. Not only that, parents cordially accept this matter. As a conservative country, the pre-marital intimate relationship was taboo at once, but now it is one of the common trends in Bangladesh.

$>$ Commitment about any love relationship is very important and it is considered as a foundation for maintaining the relationship. There is no commitment in the current relationship and technology is creating barriers to commitment. As a result of technology, young people have lots of options for entertainment.

$>$ The conflicting fact in this study with the young people regarding technology shows that technological interference in an intimate relationship may lead to conflict excessive use of technology, which may increase uncertainty into relationships and gradually it makes anxiety along with frustration.

$>$ Like the long tradition of the Bengali nation, religious values, customs, lifestyles, attitudes are disappearing gradually. Furthermore, our young people are influenced by western cultures. Through social media, young people can access the whole world easily. For this reason, young people easily get married to other religions. Not only that, they get married from other countries and they are involved in their relationship through social media.

$>$ The divorce rate has been on the rise in Bangladesh over the last decade. According to the popular daily newspaper in Bangladesh, per day 39 divorces have occurred which means one divorce per 37 minutes. It is very alarming news for everybody. According to the Bangladesh Bureau of Statistics, the divorce rate is becoming more and more among educated husbands and wives in Bangladesh. Women are educated and independent, so they do not tolerate their husband's oppression. Not only that social communication is one of the other reasons behind the increasing rate of divorce in Bangladesh.

$>$ The research was conducted in Bangladesh to explore the involvement of urban males in nonmarital or extramarital relationships. Unfortunately, an increasing number of young people are involving in intimate relationships outside of their homes. The male or female who is involved in an extramarital affair is not concerned about their future generation. Sometimes, we see in social media or newspapers that parents kill their loving children for extramarital affairs.

\section{Limitations and Further Implications}

In a conservative Muslim country like Bangladesh, young people do not want to express their intimate relationship, especially women who want to hide their intimate relationship. Besides, those who are not serious about their relationship or there is no strong commitment with their partner or involved in a complicated relationship, don't want to introduce their partner to a friend or relative or others. Here, the study explores the main objectives of the research is intimacy or intimate relationship and technological impact on youth in Dhaka city. The remarkable variations have been observed in the study based on the 
socio-demographic status between public and private universities, and also, multidimensional perceptions among themselves. The study is not beyond limitation. The first and foremost limitation is that the study of the sample was limited to young people in the intimate relationship with the high access of technology and all the respondents have been taken from Dhaka city, for this reason, the research may fail to measure that could have represented the complete picture of the research. Another limitation is that the respondents who are attached to the intimate relationship may provide wrong information that is impossible to verify. Furthermore, it can be assumed that the respondents who are interviewed in the study are diversified regarding their socio-demographic profile and economic backgrounds might have provided different perspectives.

Besides that, the study has tried to show the transformation of intimate relationships and how much technology affects this relationship on youth, but it may be less observant. Despite these limitations, the result of the present study has considerable importance as well as the findings may provide a cornerstone for doing further study in these research issues. Not only that the following recommendation and further implications may be applicable:

$>$ Most of the people of Bangladesh are Muslim. Religious practices can control the excessive use of technology and the involvement of unexpected intimate relationships. Intimacy before marriage is strictly prohibited in Islam and addiction to another woman without a wife is forbidden after marriage. Young people should achieve religious practices.

$>$ The number of divorcees has increased in the capital city. Extramarital affairs are the result of more divorces and separations. Moreover, many couples are suffering from a psychological breakdown and emotional distress with their intimate relationships.

$>$ Sociologists, psychologists, social workers can arrange the mass media-based consciousnessraising program for young people where the negative aspects of technology can be described.

$>$ Open discussions, seminars, workshops can be organized for young people on the effect of social media in every public and private University.

$>$ The government should take some steps to stop some harmful sites (like pornography) which create destruction with a young intimate relationship. Not only Government but all the people in every sector should also be conscious about the excessive use of technology. Furthermore, excessive use of technology harms peoples physically and mentally. The young people are more involved. That's why the more they are affected by its harmful effects. So, young people need to be aware of this.

\section{Conclusion}

In conclusion, this research tries to explore how technology has an essential role in changing intimate relationship patterns among the youths in Bangladesh. Everything is changeable in this world and intimate relationships between men and women are not out of it. Intimate relationship pattern varies from culture to culture; society to society and from one social stage to another. Technology has a great contribution to maintaining and developing intimate relationships. Despite the technology is a simple concept, it is very complicated to measure and it is also the blame for an interruption for the partners sometimes. Intimate relationships can be transformed by the use of technology and we are now observing these effects. The people of Bangladesh could not easily adopt this rapid transformation because of their religious values, lifestyles, customs, and ethics. For globalization, young people of Bangladesh could not completely western or Bangladeshi. Globalization accelerates cultural hybridization that leads people to mix their traditional local culture with western culture. Due to this cultural hybridization, the western pattern of intimacy easily enters our country and our young generation tries to follow this. Young people should accept the positive uses of technology and negative aspects must be eliminated. That way our intimate relationship will be healthy and more organized. 


\section{Reference}

(n.d.). Retrieved 1 4, 2021, from The Lawyers and Jurists: https://www.lawyersnjurists.com/article/hindumarriage-registration-in-bangladesh/

Afroz, S. (2019). The Rise of Divorce in Bangladesh: A Review in the Change of Marriage Dynamics. Social Sciences, 8(5), 261-269.

AHMED, A. U. (1986). MARRIAGE AND ITS TRANSITION IN BANGLADESH. International Journal of Sociology of the Family, 16, No. 1, 49-59.

Bauman, Z. (2003). Liquid Love: On the Frailty of Human Bonds. Cambridge: Polity Press.

Beck, U., \& Beck-Gernsheim, E. (1995). The Normal Chaos of Love. Cambridge: Polity Press.

blogspot.com. (n.d.). Retrieved 1 10, 2021, from http://truelovestorys.blogspot.com/2011/04/shirinfarhad.html

Countries and their Cultures. (n.d.). Retrieved 1 4, 2021, from https://www.everyculture.com/ABo/Bangladesh.html

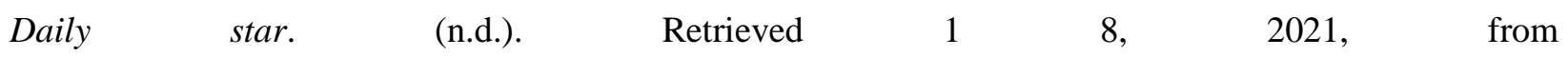
https://www.thedailystar.net/news/opinion/perspective/understanding-the-rise-divorce-bangladesh1628311\#: :text=This\%20was\%20one\%20of\%20the,Bureau\%20of\%20Statistics\%20(BBS).

FUAD, M. (2019, 9 18). Retrieved 1 9, 2021, from The independent: http://www.theindependentbd.com/post/215856

Giddens, A. (1992). In A. Giddens, The Transformation of Intimacy,Sexuality, Love, and Eroticism in Modern Societies. Stanford University Press. Retrieved from https://www.sup.org/books/cite/?id=2665

Giddens, A. (1992). The Transformation of Intimacy: Sexuality, Love, and Eroticism in Modern Societies. Stanford, California: Stanford University Press.

Giddens, A. (2006). Sociology. Cambridge: Polity Press.

Jahan, Y., Rahman, S. A., Chowdhury, S., \& Chowdhury, A. S. (2017). Factors involving extramarital affairs among married adults in Bangladesh. nternational Journal of Community Medicine and Public Health, 4(5), 1379-1386.

Jin, B., \& Peña, J. (2010). Mobile Communication in Romantic Relationships: Mobile Phone Use, Relational Uncertainty, Love, Commitment, and Attachment Styles. Communication Reports, 39-51.

Kawamichi, H., Sugawara, S., Hamano, Y., Makita, K., Matsunaga , M., Tanabe, H., . . . Sadato, N. (2016). Being in a Romantic Relationship Is Associated with Reduced Gray Matter Density in Striatum and Increased Subjective Happiness. frontiers in Psychology, 7, 1-9. doi:doi: 10.3389/fpsyg.2016.01763

Lankveld, J. v., Jacobs, N., Thewissen, V., Dewitte, M., \& Verboon, P. (2018). The associations of intimacy and sexuality in daily life: Temporal dynamics and gender effects within romantic 
relationships. Journal of Social and Personal Relationships, 35(4), 557-576. doi:https://doi.org/10.1177/0265407517743076

Mannan, M. (2020, December 25). Retrieved February 24, 2021, from The Independent: http://www.theindependentbd.com/post/257615

McDaniel, B. T., \& Coyne , S. (2016). "Technoference": The interference of technology in couple relationships and implications for women's personal and relational well-being. Psychology of Popular Media Culture, 5(1), 85-98.

MediaBangladesh.net. (n.d.). Retrieved 1 10, 2021, from https://www.mediabangladesh.net/dhaka-citymap-south-and-north-city-corporation/

Muniruzzaman, M. (2017). Transformation of intimacy and its impact in developing countries. Life Sciences, Society and Polocy, 13(10), 1-19. doi:https://doi.org/10.1186/s40504-017-0056-8

N.Duerksen, K., \& Woodin, E. (2019). Technological intimate partner violence: Exploring technologyrelated perpetration factors and overlap with in-person intimate partner violence. Computers in Human Behavior, 98, 223-231. doi:https://doi.org/10.1016/j.chb.2019.05.001

Nowshin, N. (2018, September 3). Retrieved February 24, 2021, from The Daily Star: https://www.thedailystar.net/news/opinion/perspective/understanding-the-rise-divorce-bangladesh1628311

Pervin, I., \& Hussain, R. (2018). Web Technology and the Changing Pattern of. International Journal of Research and Innovation in Social Science (IJRISS), 2(12), 449-453.

Prothom Alo.com. (2018, 8 28). Retrieved 1 10, 2021, from https://en.prothomalo.com/bangladesh/Onedivorce-in-Dhaka-every-hour

Rossouw, P., \& Leggett, C. (2014). The Impact of Technology Use on Couple Relationships: A Neuropsychological Perspective. International Journal of Neuropsychotherapy, 2(1), 44-99. doi:doi: 10.12744/ijnpt.2014.0044-0099

Wallerstein, I. (1989). The Modern World-System III: The Second Era of Great Expansion of the Capitalist World-Economy, 1730s-1840s. Cambridge : Academic Press .

\section{Copyrights}

Copyright for this article is retained by the author(s), with first publication rights granted to the journal.

This is an open-access article distributed under the terms and conditions of the Creative Commons Attribution license (http://creativecommons.org/licenses/by/4.0/). 